\title{
E-Selectin plasma concentration is influenced by glycaemic control in NIDDM patients: possible role of oxidative stress
}

\author{
L. Cominacini ${ }^{1}$, A . Fratta Pasini ${ }^{1}$, U . G arbin ${ }^{1}$, M . Campagnola ${ }^{1}$, A . D avoli ${ }^{1}$, A . R igoni, M . G . Z enti ${ }^{2}$, A . M . Pastorino ${ }^{3}$, \\ V. Lo C ascio ${ }^{1}$ \\ ${ }^{1}$ Istituto di Semeiotica e Nefrologia Medica, Verona, Italy \\ ${ }^{2}$ Cattedra di Malattie del Metabolismo, Università di Verona, Verona, Italy \\ ${ }^{3}$ Glaxo Wellcome SpA, Centro Ricerche, Verona, Italy
}

Summary Although elevated levels of soluble E-selectin and intercellular cell adhesion molecules-1 (ICAM-1) have been reported in non-insulin-dependent diabetes mellitus (NIDDM), it is not clear by what mechanism this elevation occurs and whether or not it is related to glycaemic control. In this study we analyse: 1) the relation of glycaemic control with the concentrations of E-selectin, vascular cell adhesion molecules-1 (VCAM-1) and ICAM-1 in NIDDM patients; 2) whether metabolic control can affect the oxidative stress (as measured by plasma hydroperoxide concentration and susceptibility of LDL to in vitro oxidation) and hence the adhesion molecule plasma concentrations. Thirty-four (19 males and 15 females) poorly controlled NIDDM patients were studied. All parameters were evaluated at the beginning of the study and after 90 days of dietary and pharmacological treatment. The treatment decreased $\mathrm{HbA}_{1 \mathrm{C}}(\mathrm{p}<0.001)$, E-selectin $(p<0.001)$, plasma hydroperoxides $(p<0.003)$ and the susceptibility of LDL to in vitro oxidation (lag phase) $(p<0.0001)$. Before treatment $\mathrm{HbA}_{1 \mathrm{C}}$, lag phase and lipid hydroperoxides correlated with E-selectin plasma concentration $(r=0.51,-0.57$ and 0.54 , respectively, $\mathrm{p}<0.01)$. There was also a correlation between
$\mathrm{HbA}_{1 \mathrm{C}}$ and lag phase $(\mathrm{p}<0.01)$ and between $\mathrm{HbA}_{1 \mathrm{C}}$ and lipid hydroperoxides $(p<0.01)$. In addition, the variations of $\mathrm{HbA}_{1 \mathrm{C}}$, lag phase and lipid hydroperoxide values correlated with those for E-selectin concentration after 90 days' treatment $(r=0.54,-0.64$ and 0.61 , respectively, $p<0.01$ ). In multiple linear correlation analysis, however, the partial correlation coefficients of $\mathrm{HbA}_{1 \mathrm{C}}$ (basal and variations) with Eselectin concentration (basal and variations) fell to non-significant values $(r=0.12$ and 0.25 , respectively) when LDL lag phase and plasma hydroperoxides were kept constant. The results indicate that the improvement of metabolic control in NIDDM patients is associated with a decrease of E-selectin plasma levels; they also suggest that glycaemic control per se is not directly implicated in determining E-selectin plasma concentration; glycaemic control could affect E-selectin concentration through its effect on oxidative stress. [Diabetologia (1997) 40: 584-589]

Keywords E-selectin, intercellular cell adhesion molecules-1, vascular cell adhesion molecules-1, non-insulin-dependent diabetes mellitus, glycaemic control, plasma hydroperoxides, susceptibility of LDL to oxidation.
Received: 31 October 1996 and in revised form 23 January 1997

Corresponding author: Dr. L. Cominacini, Istituto di Semeiotica e Nefrologia Medica, Ospedale Policlinico, I-37134 Verona, Italy

Abbreviations: EDTA, Ethylendiamine tetraacetic acid; ICAM-1, Intercellular cell adhesion molecules-1; NIDDM, non-insulin-dependent diabetes mellitus, VCAM-1, vascular cell adhesion molecules-1.
Atherosclerosis is the major cause of death in patients with diabetes mellitus, accounting for more than $70 \%$ of mortality in all forms of the disease $[1,2]$. There is plenty of evidence that monocytes are involved in the pathogenesis of atherosclerosis $[3,4]$, the earliest morphological evidence of the disease being the binding of monocytes to the endothelium [57]. This adhesion of monocytes, a prerequisite for their recruitment and accumulation in the lesion, is probably due to the appearance of adhesion 
molecules at the cell surface. These adhesion molecules include intercellular cell adhesion molecules-1 (ICAM-1) and vascular cell adhesion molecules-1 (VCAM-1), which are the products of endothelial and other cells, as well as E-selectin, a specific product of endothelial cells $[8,9]$.

Increased levels of serum adhesion molecules have recently been detected in patients with or at risk of developing atherosclerosis [10-12]. Increased levels of E-selectin, ICAM-1 and VCAM-1 have also been found in patients with insulin-dependent diabetes and non-insulin-dependent diabetes (NIDDM) $[10,13-15]$ but it is still unclear whether this increase is related to glycaemic control. In poorly controlled diabetic patients, excess glucose causes enhanced glycation of plasma proteins. This non-enzymatic glycation of proteins has been presumed to cause an enhanced oxidative stress, through generation of oxygen free radicals [16-19]. An enhanced oxidative stress, i.e. increased levels of plasma hydroperoxides, has actually been observed in NIDDM [20-24]. The augmented generation of free radicals could also result in oxidative damage of LDL, the known potentially atherogenic properties of oxidized LDL including monocyte recruitment [25] and modulation of expression of adhesion molecules [26, 27]. Enhanced susceptibility of LDL to oxidation has recently been reported in diabetic patients [24, 28, 29].

The present study analyses the relationship of glycaemic control to concentrations of E-selectin, VCAM-1 and ICAM-1 in NIDDM patients. The study also addresses whether glycaemic control can affect the oxidative stress, and hence adhesion molecule plasma concentrations, in NIDDM patients.

\section{Patients and methods}

Patients. Thirty-four NIDDM patients in poor metabolic control were studied. The subjects (19 males and 15 females) with a mean history of diabetes of $9.5 \pm 4.7$ years, had a mean age of $57.5 \pm 10.2$ years and a body mass index (BMI) calculated from weight $/ \mathrm{height}^{2}$ of $29.2 \pm 5.1 \mathrm{~kg} / \mathrm{m}^{2}$. All participants reported only occasional alcohol intake; of the 34 patients only 3 reported occasionally smoking (not more than 2 cigarettes for the study period); in addition, it was ascertained that they had no renal impairment, liver disease, clinical symptoms of coronary artery disease and peripheral artery disease, hyperlipidaemia or pathological processes known to increase adhesion molecules. Informed written consent was obtained from all participants. At the time of examination, details of blood pressure and use of hypotensive medications were recorded. Fourteen NIDDM patients had hypertension and were under treatment with calcium antagonists and angiotensin-converting enzyme inhibitors. All subjects were advised to consume a lipid-lowering diet before their admission to the study. The diet was isocaloric and contained $25 \%$ of energy as fat, $15 \%$ of energy as protein and $60 \%$ of energy as carbohydrate $(80 \%$ as complex carbohydrates). The ratio of polyunsaturated to saturated fatty acids was 0.5 . The dietary compliance was monitored during the treatment period by a specially trained dietician who collected 3-day diet histories and 2-week daily dietary records every 15 days as previously described [30].

Twenty-four patients were treated either with anti-diabetic oral sulphonylureas alone $(n=6)$, in combination with metformin $(n=15)$ or with insulin $(n=3) ; 7$ patients were treated with three daily insulin injections and 3 patients had no antidiabetic medication. Fasting plasma and lipoprotein lipids, glucose, glycated haemoglobin $\left(\mathrm{HbA}_{1 \mathrm{C}}\right)$, susceptibility of LDL to oxidation, plasma hydroperoxides and adhesion molecules (E-selectin, VCAM-1 and ICAM-1) were evaluated at the beginning of the study and after 90 days of dietary and pharmacological treatment. Fasting plasma glucose was also monitored every 4 weeks during the 90 -day treatment regimen.

M ethods. Whole blood was collected into vacutainer tubes containing ethylendiamine tetraacetic acid (EDTA) $(1 \mathrm{mg} / \mathrm{ml})$ and immediately centrifuged at $2000 \mathrm{rev} / \mathrm{min}$ for $20 \mathrm{~min}$ at $4{ }^{\circ} \mathrm{C}$. Plasma was stored at $4{ }^{\circ} \mathrm{C}$ and processed for lipoprotein separation within 1 day. Lipoproteins were isolated by sequential ultracentrifugation in $\mathrm{NaBr}$ solutions [31] containing $1 \mathrm{mg} /$ $\mathrm{ml}$ EDTA, stored at $4{ }^{\circ} \mathrm{C}$ and used within 4 days. Cholesterol and triglycerides in plasma and lipoprotein fractions were determined by Technicon autoanalyser II methodology [32, 33]. Glucose in plasma was measured by the glucose oxidase method on the Beckman glucose analyser [34]. $\mathrm{HbA}_{1 \mathrm{C}}$ in plasma was measured by a minicolumn chromatographic procedure [35].

The method evaluating the susceptibility of LDL to oxidation (expressed as lag phase in minutes) is based on development of fluorescence during copper-catalysed LDL oxidative modification, as described elsewhere [36]. Based on the fluorescence development from 0 to $260 \mathrm{~min}$, the duration of the lag phase was calculated as described previously [36].

Plasma hydroperoxides were measured as the thiobarbituric acid adduct, by a published high performance liquid chromatography (HPLC) method [37, 38]. Analytical separations were performed with a Hewlett-Packard 1050 connected to a reverse phase $\mathrm{C} 18,15 \times 0.46 \mathrm{~cm}$ (Bio-Rad, Hercules Calif., USA); the system included a guard column (Microguard System, Bio-Rad), with a Hewlett-Packard spectrophotometric UV-VIS detector at $532 \mathrm{~nm}$ (Boise, Idaho, USA). Malonyldialdehyde (MDA) standard was prepared by dissolving $220.3 \mathrm{mg}$ of 1,1,3,3-tetraethoxypropane (Aldrich-Chemie, Steinheim, Germany) in $100 \mathrm{ml}$ of deionized water, to give a $10 \mathrm{mmol} / \mathrm{l}$ stock solution.

Concentrations of soluble E-selectin, ICAM-1 and VCAM1 were estimated using the soluble E-selectin, ICAM-1 and VCAM-1 ELISA kits (British Bio-technology Products Ltd, Abingdon-Oxon, UK), as previously described [15]. The assay is standardized against purified soluble forms of recombinant E-selectin, VCAM-1 and ICAM-1. The intra-assay coefficients of variation for all ELISA assays were less than $4 \%$.

\section{Statistical analysis}

Values are expressed as mean \pm SD. Statistical differences between data obtained before and after treatment were tested using Student's t-test for paired data. This test was applied after the distribution of the differences of each investigated parameter was demonstrated to be normal by means of the Kolmogorov-Smirnov one-sample test [39]. The relationships among the considered variables were studied using linear partial and multiple correlation analysis as previously described [40, 41]. Parameters were estimated by using the Systat program and 
Table 1. Clinical and biochemical characteristics of subjects before and after dietary and pharmacological treatment

\begin{tabular}{lrrl}
\hline & \multicolumn{1}{l}{ Before } & \multicolumn{1}{l}{ After } & p value \\
\hline Body mass index $\left(\mathrm{kg} / \mathrm{m}^{2}\right)$ & $29.2 \pm 5.1$ & $28.5 \pm 4.3$ & $\mathrm{NS}$ \\
Glucose $(\mathrm{mmol} / \mathrm{l})$ & $9.7 \pm 2.4$ & $7.5 \pm 1.7$ & 0.001 \\
HbA $_{1 \mathrm{C}}(\%)$ & $7.4 \pm 1.6$ & $6.4 \pm 1.3$ & 0.001 \\
Cholesterol $(\mathrm{mmol} / \mathrm{l})$ & $5.7 \pm 0.1$ & $5.6 \pm 0.6$ & $\mathrm{NS}$ \\
Triglycerides $(\mathrm{mmol} / \mathrm{l})$ & $1.9 \pm 0.9$ & $1.8 \pm 0.8$ & $\mathrm{NS}$ \\
LDL Chol $(\mathrm{mmol} / \mathrm{l})$ & $3.9 \pm 1.0$ & $4.0 \pm 0.9$ & $\mathrm{NS}$ \\
HDL Chol $(\mathrm{mmol} / \mathrm{l})$ & $1.1 \pm 0.4$ & $1.0 \pm 0.3$ & $\mathrm{NS}$ \\
\hline
\end{tabular}

Data are mean \pm SD

Table 2. LDL lag phase, plasma hydroperoxides, E-selectin, ICAM-1 and VCAM-1, before and after dietary and pharmacological treatment

\begin{tabular}{lccl}
\hline & Before & After & p value \\
\hline LDL lag phase $(\mathrm{min})$ & $80.8 \pm 12.8$ & $101.6 \pm 17.1$ & 0.0001 \\
Hydroperoxides $(\mathrm{nmol} / \mathrm{ml})$ & $0.75 \pm 0.15$ & $0.62 \pm 0.16$ & 0.003 \\
E-selectin $(\mathrm{ng} / \mathrm{ml})$ & $87.7 \pm 21.4$ & $70.1 \pm 20.5$ & 0.001 \\
ICAM-1 $(\mathrm{ng} / \mathrm{ml})$ & $472.7 \pm 147.6$ & $473.4 \pm 189.1$ & NS \\
VCAM-1 $(\mathrm{ng} / \mathrm{ml})$ & $467.1 \pm 210.3$ & $437.3 \pm 221.9$ & NS \\
\hline
\end{tabular}

Data are mean \pm SD

manual for Macintosh (Systat Inc., Evanston, Ill., USA). The method used by Systat is called 'ordinary least squares', a method that minimizes the sum of the squared residuals. The $\mathrm{R}$ is the multiple Pearson correlation coefficient. Significance tests are based on the calculation of the 'standard error of estimate'. The significance of the entire model was tested employing the analysis of variance ( $\mathrm{F}$ ratio).

The partial correlation of $n$ independent variables given a dependent variable is the correlation between the residuals of each independent variable after each has been regressed on the dependent variable. Systat calculates the partial correlation by means of 'the residual correlation matrix'; it is the matrix of partial correlations among the $y$ 's given $x$.

\section{Results}

The anthropometric characteristics of the patients, as well as glucose concentration, percentage $\mathrm{HbA}_{1 \mathrm{C}}$ values and lipid profile at the beginning and at the end of the study are shown in Table 1 . After the 90 days of treatment, no significant variation in total plasma cholesterol, triglycerides, LDL cholesterol and HDL cholesterol was observed. $\mathrm{HbA}_{1 \mathrm{C}}$ and glucose concentrations were reduced from $7.4 \pm 1.6$ to $6.4 \pm$ $1.3 \% \quad(p<0.001)$ and from $9.7 \pm 2.4$ to $7.5 \pm$ $1.7 \mathrm{mmol} / \mathrm{l}(p<0.001)$, respectively. Table 2 shows the values of LDL lag phase, plasma hydroperoxides, E-selectin, VCAM-1 and ICAM-1 before and after treatment. The diet and the pharmacological treatment determined a significant increase in LDL lag phase $(p<0.0001)$ and a significant decrease in plasma hydroperoxides $(p<0.003)$. Among the adhesion molecules, only E-selectin was significantly decreased after the 90 days' treatment $(p<0.001)$.

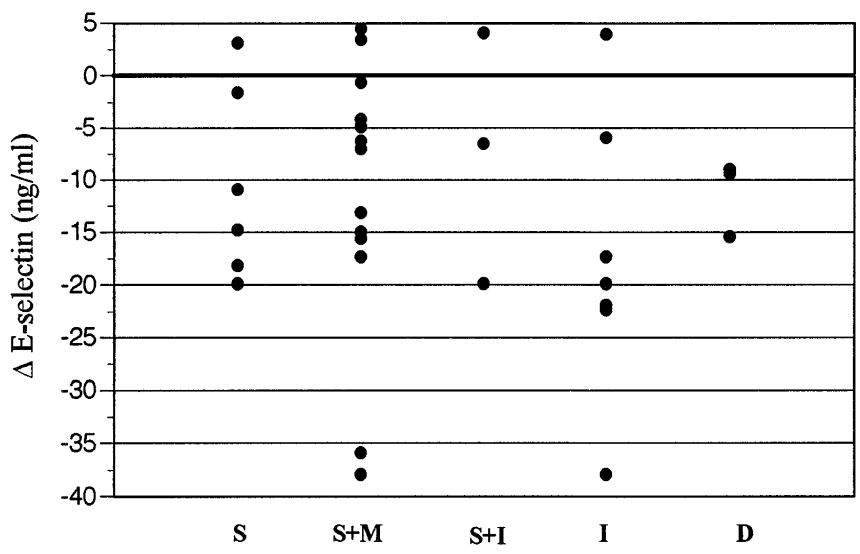

Fig. 1. Influence of different treatments ( $S$, Sulphonylureas; $\mathrm{S}+\mathrm{M}$, sulphonylureas + metformin; $\mathrm{S}+\mathrm{I}$, sulphonylureas + insulin; I, insulin; D, diet alone) on E-selectin variation $(\Delta)$

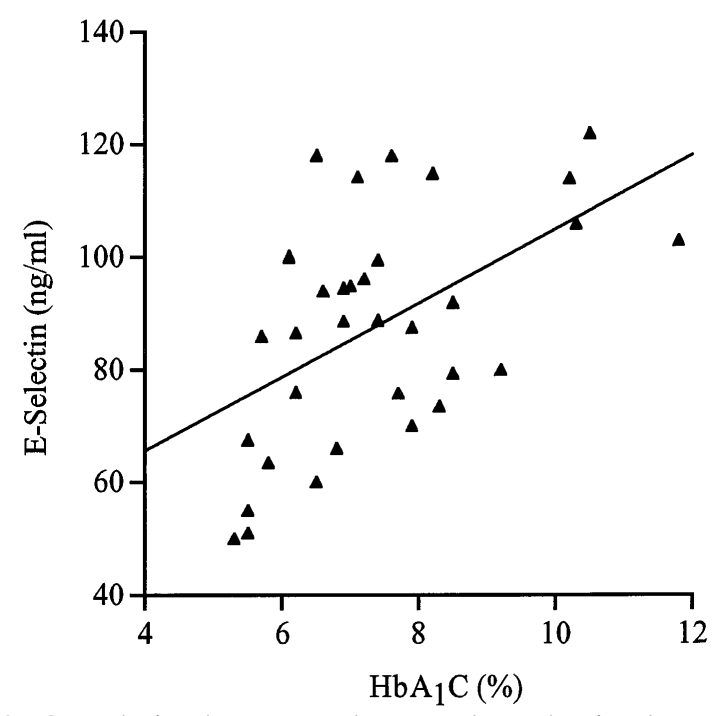

Fig. 2. Correlation between $\mathrm{HbA}_{1 \mathrm{C}}$ and E-selectin plasma concentration at the beginning of the study $(r=0.51, p<0.01)$

Figure 1 shows how the different treatments influenced E-selectin in each patient.

At the beginning of the study $\mathrm{HbA}_{1 \mathrm{C}}$, LDL lag phase and plasma hydroperoxides were positively correlated with E-selectin $(r=0.51, p<0.01 ; r=$ $-0.57, p<0.01 ; r=0.54, p<0.01$, respectively) (Figs. $2-4)$ but not with VCAM-1 or ICAM-1. We found also a positive correlation of $\mathrm{HbA}_{1 \mathrm{C}}$ with $\mathrm{LDL}$ lag phase $(r=0.53, p<0.01)$ and plasma hydroperoxides $(r=0.50, p<0.01)$.

To evaluate the interrelationships among these variables, a multiple regression model was fitted to the data, using $\mathrm{HbA}_{1 \mathrm{C}}$, LDL lag phase and plasma hydroperoxides as independent variables and E-selectin as a dependent variable. In particular in this study we applied the partial correlation analysis to the data. In a multiple linear model: $Y=\alpha+\beta_{1} x_{1}+\beta_{2} x_{2}$ $+\ldots \ldots .+\beta_{\mathrm{n}} \mathrm{x}_{\mathrm{n}}+\varepsilon$, the constants $\beta_{1}, \beta_{2} \ldots \beta_{\mathrm{n}}$ are called 


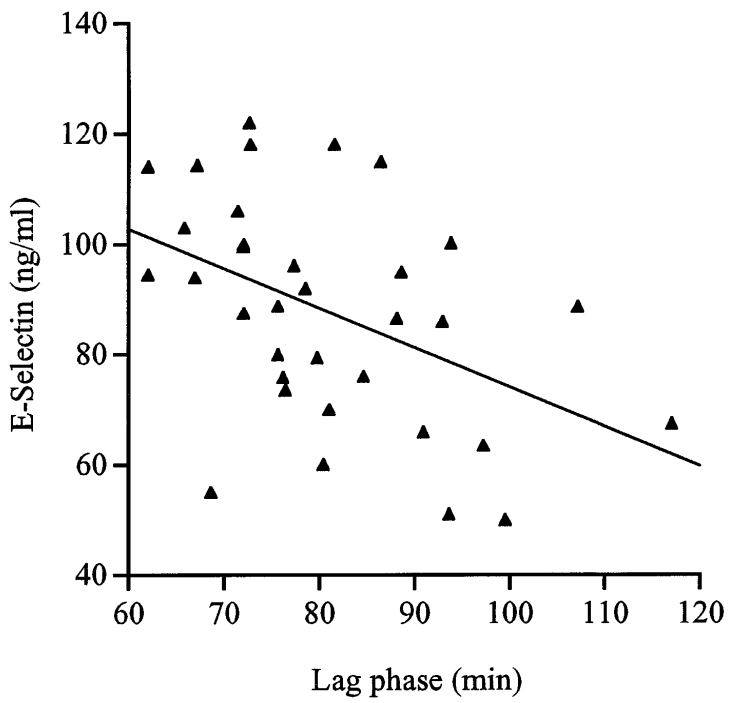

Fig. 3. Correlation between LDL lag phase and E-selectin plasma concentration at the beginning of the study $(r=-0.57$, $\mathrm{p}<0.01)$

partial correlation coefficients. The coefficient $\beta_{1}$ corresponds to the variation (increase or decrease) of the average value of $\mathrm{y}$ when $\mathrm{x}_{1}$ rises of one unit while the other $x_{i}$ remain constant. While, therefore, in multiple regression, several independent variables impact one dependent variable, in partial correlation analysis the correlation between a dependent (y) and an independent variable $\left(\mathrm{x}_{1}\right)$ is controlled for the other variables $\left(\mathrm{x}_{2}\right)$ of the multiple regression. Table 3 shows the simple and partial correlation coefficients between each of the independent variables $\left(\mathrm{HbA}_{1 \mathrm{C}}, \mathrm{LDL}\right.$ lag phase and plasma hydroperoxides) and the dependent variable (E-selectin). When the partial correlation analysis was applied and LDL lag phase and plasma hydroperoxides were kept constant, $\mathrm{HbA}_{1 \mathrm{C}}$ was no longer correlated with E-selectin (simple linear correlation coefficient $=0.51$, $p<0.01$; partial correlation coefficient $=0.12$ ). The partial correlation coefficient of the LDL lag phase decreased to $-0.51(p<0.01)$ (simple linear correlation coefficient $=-0.57, \mathrm{p}<0.01)$, and the partial correlation coefficient of plasma hydroperoxides to 0.49 $(p<0.01)$ (simple linear correlation coefficient $=$ $0.54, p<0.01)$.

After 90 days' treatment the correlations between $\mathrm{HbA}_{1 \mathrm{C}}$ and E-selectin and between the parameters

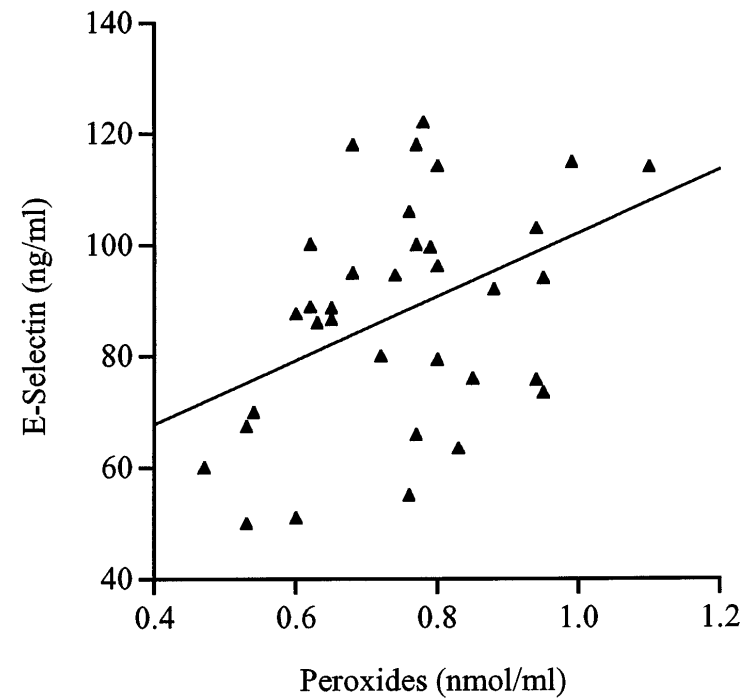

Fig. 4. Correlation between plasma hydroperoxides and E-selectin plasma concentration at the beginning of the study $(r=0.54, p<0.01)$

correlated with oxidative stress and E-selectin were lost.

The variations in each of the independent variables $\left(\mathrm{HbA}_{1 \mathrm{C}}\right.$, LDL lag phase and plasma hydroperoxides), however, correlated with those of the dependent variable (E-selectin) $(r=0.54, p<0.01 ; r=$ $-0.64, p<0.01 ; r=0.61, p<0.01$ respectively). Similarly, variations in $\mathrm{HbA}_{1 \mathrm{C}}$ correlated with those in LDL lag phase $(r=0.48, p<0.01)$ and plasma hydroperoxides $(r=0.40, p<0.01)$.

A multiple regression model for the evaluation of the correlation coefficients was also fitted to these data, using the variations in $\mathrm{HbA}_{1 \mathrm{C}}$, LDL lag phase and plasma hydroperoxides as independent variables and the variation in E-selectin as a dependent variable (Table 4). When the variations in LDL lag phase and plasma hydroperoxides were kept constant, the variation in $\mathrm{HbA}_{1 \mathrm{C}}$ was no longer correlated with that for E-selectin (simple correlation coefficient $=$ $0.54, p<0.01$; partial correlation coefficient $=0.25$ ). The partial correlation of LDL lag phase variation decreased to $-0.51(p<0.01)$ (simple linear correlation coefficient $=-0.64, p<0.01)$, and the partial correlation of plasma hydroperoxides to $0.58(p<0.01)$ (simple linear correlation coefficient $=0.61$, $\mathrm{p}<0.01)$.

Table 3. Simple and partial correlation coefficients between each of the independent variables and E-Selectin (dependent variable)

\begin{tabular}{lclr}
\hline Independent variables & Simple correlation & Constant & Partial correlation \\
\hline $\mathrm{HbA}_{1 \mathrm{C}}$ & $0.51^{\mathrm{a}}$ & LDL lag phase, peroxides & 0.12 \\
LDL lag phase & $-0.57^{\mathrm{a}}$ & $\mathrm{HbA}_{1 \mathrm{C}}$, peroxides & $-0.51^{\mathrm{a}}$ \\
Peroxides & $0.54^{\mathrm{a}}$ & $\mathrm{HbA}_{1 \mathrm{C}}$, LDL lag phase & $0.49^{\mathrm{a}}$ \\
\hline
\end{tabular}

a $p<0.01$ 
Table 4. Simple and partial correlation coefficients between the variations $(\Delta)$ of each of the independent variables and the $\Delta$ of the dependent variable (E-selectin)

\begin{tabular}{lllr}
\hline Independent variables & Simple correlation & Constant & Partial correlation \\
\hline$\Delta \mathrm{HbA}_{1 \mathrm{C}}$ & $0.54^{\mathrm{a}}$ & $\Delta$ LDL lag phase, $\Delta$ peroxides & 0.25 \\
$\Delta$ LDL lag phase & $-0.64^{\mathrm{a}}$ & $\Delta \mathrm{HbA}_{1 \mathrm{C}}, \Delta$ peroxides & $-0.51^{\mathrm{a}}$ \\
$\Delta$ Peroxides & $0.61^{\mathrm{a}}$ & $\Delta \mathrm{HbA}_{1 \mathrm{C}}, \Delta$ LDL lag phase & $0.58^{\mathrm{a}}$ \\
\hline
\end{tabular}

${ }^{\mathrm{a}} \mathrm{p}<0.01$

\section{Discussion}

The results of this study show that the plasma concentration of E-selectin significantly decreased after a period of pharmacological and dietary treatment that induced an improvement of glycaemic control. On the basis of the present results, assessing the mechanisms and the physiological significance, if any, of this decrease, is problematic. Since a correlation between $\mathrm{HbA}_{1 \mathrm{C}}$ and E-selectin plasma concentration was found, a first tentative explanation of our results may be that glycaemic control per se may, somehow, affect the plasma concentration of this adhesion molecule. These results are in agreement with our previous results, in which a correlation between $\mathrm{HbA}_{1 \mathrm{C}}$ and E-selectin was found in a small group of NIDDM patients [15]. Similar results were also obtained by Fasching et al. [42] in 159 NIDDM patients. Contrary to our [15] and Fasching's [42] results, in another recently published paper [14], the levels of soluble adhesion molecules failed to correlate with glycaemic control. Actually soluble concentration of Eselectin was found in this study to be related not only to glycaemic control, i.e $\mathrm{HbA}_{1 \mathrm{C}}$, but also to plasma hydroperoxides and to susceptibility of LDL to oxidation. To evaluate the interrelationships among these variables, a multiple regression model was fitted to the data, using $\mathrm{HbA}_{1 \mathrm{C}}$, LDL lag phase and plasma hydroperoxides as independent variables and E-selectin as dependent variable. The analysis showed that the partial correlation coefficient with $\mathrm{HbA}_{1 \mathrm{C}}$ fell to non-significant values when it was controlled for the variables evaluated to assess oxidative stress. Although correlative analysis cannot be used to prove a causal relationship, the results suggest that oxidative stress more than glycaemic control may be a determinant of E-selectin plasma concentration.

This conclusion is supported by the results we obtained after satisfactory metabolic control was achieved. Besides a reduction of soluble E-selectin concentration, the dietary and pharmacological treatment produced a significant decrease in plasma hydroperoxides and in LDL oxidation. The variation of $\mathrm{HbA}_{1 \mathrm{C}}$ was found to be correlated to the variation in E-selectin plasma concentration, as well as to the decrease in the parameters evaluated to assess oxidative stress. Also in this case, the fact that the variations in plasma hydroperoxides and LDL oxidation abolish the correlation between the variations in $\mathrm{HbA}_{1 \mathrm{C}}$ and soluble E-selectin, indicates that the influence of $\mathrm{HbA}_{1 \mathrm{C}}$ on E-selectin may be mediated.

In support of this view the results of this study also demonstrate that there was a positive correlation between $\mathrm{HbA}_{1 \mathrm{C}}$ with LDL lag phase and plasma hydroperoxides. Enhanced oxidative stress, as monitored by increased levels of plasma hydroperoxides [20 24] and increased susceptibility of LDL to oxidation, has already been reported in diabetic patients [24, 29]. In diabetic patients in poor control, excess glucose causes an enhancement of the glycation of plasma protein and this non-enzymatic glycation of proteins has been presumed to cause enhanced oxidative stress, through generation of oxygen free radicals [16-19]. Byproducts of lipid peroxidation, such as conjugated dienes and thiobarbituric-acid-reactive substances, could therefore derive from the non-enzymatic glycation of proteins, generating oxygen free radicals. This mechanism may also affect the susceptibility of LDL to oxidation. The role of copper ions in the oxidative process of LDL is, in fact, to catalyse the conversion of trace amounts of preformed plasma hydroperoxides to alkoxy and peroxy radicals, which in turn initiate another round of lipid peroxidation [43]. Glycaemic control in NIDDM patients could therefore be related to E-selectin plasma concentration, through its effect on the parameters correlated to oxidative stress. In this context, exciting recent findings indicated that oxidized LDL and plasma hydroperoxides can affect the expression of adhesion molecules on endothelial cells in vitro [26, 27]. Additional evidence that the adhesion molecule expression on endothelial cells is an oxidative stress-responsive event comes from the inhibitory effects of various structural antioxidants in response to many different stimuli [27]. Glycaemic control could, therefore, affect soluble adhesion molecule concentration through its effect on oxidative stress; it is likely, in fact, that glycaemic control can favourably affect oxidative stress by reducing glycation and therefore free radical production [19]. The decrease of free radical production and the consequent fall in lipid peroxide generation can in turn reduce the expression of E-selectin on endothelial cells.

In conclusion, the results of this study show that there is a relationship between metabolic control and soluble E-selectin concentration; this relationship is mediated by the effect of glycaemic control 
on oxidative stress, which may affect endothelial cell activity.

\section{References}

1. Steiner C (1981) Diabetes and atherosclerosis. Diabetes 30 [Suppl 2]: 1-7

2. Steiner C (1985) Atherosclerosis, the major complication of diabetes. Adv Exp Med Biol 189: 277-297

3. Ross R (1986) The pathogenesis of atherosclerosis - an update. N Engl J Med 314: 488-500

4. Rubanyi GM (1996) The role of endothelium in cardiovascular homeostasis and diseases. J Cardiovasc Pharmacol 23 [Suppl 2] S1-S14

5. Gerrity RG (1981) The role of monocyte in atherogenesis. I. Transition of blood-borne monocytes into foam cells in fatty lesions. Am J Path 103: 181-190

6. Joris I, Zand T, Nunnari JJ, Krolikowsky FJ, Majno G (1983) Studies on the pathogenesis of atherosclerosis I. Adhesion and migration of mononuclear cells in the aorta of hypercholesterolemic rats. Am J Path 113: 341-358

7. Faggiotto A, Ross R, Harker L (1984) Studies of hypercholesterolemia in the nonhuman primate. Arteriosclerosis 4: 323-340

8. Springer TA (1990) Adhesion receptors of the immune system. Nature 346: 425-434

9. Bevilacqua MP (1993) Endothelial-leukocyte adhesion molecules. Annu Rev Immunol 1: 767-804

10. Gearing AJH, Hemingway I, Pigott R, Hughes J, Rees AJ, Cashman SJ (1992) Soluble forms of vascular adhesion molecules, Eselectin, ICAM-1 and VCAM-1: pathological significance. Annals NY Acad Sci 667: 324-331

11. Gearing AH, Newman W (1993) Circulating adhesion molecules in disease. Immunol Today 14: 506-512

12. Blann AD, Tse W, Maxwell SJR, Waite MA (1994) Increased levels of the soluble adhesion molecule E-selectin in essential hypertension. J Hypertension 12: 925-928

13. Lampeter ER, Kishimoto TK, Rothlein R, et al. (1992) Elevated levels of circulating adhesion molecules in IDDM patients and in subjects at risk for IDDM. Diabetes 41: 1668-1671

14. Steiner M, Reinhardt KM, Krammer B, Ernst B, Blann AD (1994) Increased levels of soluble adhesion molecules in type 2 (non-insulin dependent) diabetes mellitus are independent of glycaemic control. Thromb Haemost 72: 979-984

15. Cominacini L, Fratta Pasini A, Garbin U, et al. (1995) Elevated levels of soluble E-selectin in patients with IDDM and NIDDM: relation to metabolic control. Diabetologia 38: 1122-1124

16. Wolff SP, Dean RT (1987) Glucose autoxidation and protein modification: the potential role of 'autoxidative glycosylation' in diabetes mellitus. Biochem J 245: 243-250

17. Hunt J, Wolff SP (1991) Oxidative glycation and free radical production: a causal mechanism of diabetic complications. Free Rad Res Commun 12-13: 115-123

18. Sakurai T, Kimura S, Nakans M, Kimura H (1991) Oxidative modification of glycated low density lipoprotein in presence of iron. Biochem Biophys Res Commun 177: 433-439

19. Lyons TJ (1992) Lipoprotein glycation and its metabolic consequences. Diabetes 41 [Suppl 2]: 67-73

20. Baynes JW (1991) Role of oxidative stress in development of complications in diabetes. Diabetes 40: 405-412

21. Noberasco G, Odetti P, Boeri D, Maiello M, Adezati L (1991) Malondialdehyde (MDA) level in diabetic subjects. Relationship with blood glucose and glycosylated hemoglobin. Biomed Pharmacother 45: 193-196

22. Griesmacher A, Kindhauser M, Andert SE et al. (1995) Enhanced serum levels of thiobarbituric- acid-reactive substances in diabetes mellitus. Am J Med 98: 469-475

23. Nourooz-Zadeh J, Tajaddini-Sarmadi J, McCarthy S, Betteridge JD, Wolff SP (1995) Elevated levels of authentic plasma hydroperoxides in NIDDM. Diabetes 44: 1054-1058
24. Beaudeux J-L, Guillausseau P-J, Peynet J et al. (1995) Enhanced susceptibility of low-density lipoprotein to in vitro oxidation in type 1 and type 2 diabetic patients. Clin Chim Acta 239: 131-141

25. Quinn M, Parthasarathy S, Fong LG, Steinberg D (1987) Oxidatively modified low density lipoproteins: a potential role in recruitment and retention of monocyte/macrophages during atherogenesis. Proc Natl Acad Sci 84: 2995-2998

26. Khan BV, Parthasarathy SS, Alexander RW, Medford RM (1995) Modified low density lipoprotein and its constituents augment cytokine-activated vascular cell adhesion molecule-1 gene expression in human vascular endothelial cells. J Clin Invest 95: $1262-1270$

27. Cominacini L, Garbin U, Fratta Pasini A et al.(1997) Antioxidants inhibit the expression of intercellular cell adhesion molecule- 1 and vascular cell adhesion molecule- 1 induced by oxidized LDL on human umbilical vein endothelial cells. Free Rad Biol Med 22: 117-127

28. Babiy AV, Gebicky JM, Sullivan DR (1992) Increased oxidazibility of plasma lipoproteins in diabetic patients can be decreased by probucol therapy and is not due to glycation. Biochem Pharmacol 43: 995-1000

29. Cominacini L, Garbin U, Pastorino AM et al. (1994) Increased susceptibility of LDL to in vitro oxidation in patients with insulin-dependent and non-insulin-dependent diabetes mellitus. Diabetes Res 26: 173-184

30. Cominacini L, Zocca I, Garbin U et al. (1988) Long-term effect of a low-fat, high carbohydrate diet on plasma lipids of patients affected by familial endogenous hypertriglyceridemia. Am J Clin Nutr 48: 57-65

31. Havel RJ, Eder MA, Bragdon JM (1955) The distribution and chemical composition of ultracentrifugally separated lipoproteins in human serum. J Clin Invest 34: 1345-1353

32. Block WD, Jarret MJ Jr, Levine JR (1974) Use of a single color reagent to improve the automated determination of serum total cholesterol. In: Skeggs LT Jr (ed) Automation in analytical chemistry. Mediad, New York, pp 345-353

33. Kessler G, Lederer H (1965) Fluorimetric measurement of triglycerides. In: Skeggs LT Jr (ed) Automation in analytical chemistry. Mediad, New York, pp 341-350

34. Huggett ASG, Nixon DA (1957) Use of glucose oxidase, peroxidase and O-dianisidine in determination of blood and urinary glucose. Lancet 2: 368-370

35. Jaynes PK, Willis MC, Chou PP (1985) Evaluation of a column chromatographic procedure for the measurement of hemoglobin. Alc Chim Biochem 18: 32-36

36. Cominacini L, Garbin U, Davoli A, Micciolo R, Bosello O, Gaviraghi G (1991) A simple test for predisposition to LDL oxidation based on the fluorescence development during copper-catalysed oxidative modification. J Lipid Res 32: 349-358

37. Carbonneau MA, Peuchant E, Sess D, Canioni P, Clerc M (1991) Free and bound Malondialdeyde measured as thiobarbituric acid adduct by HPLC. Clin Chem 37: 1423-1429

38. Cominacini L, Garbin U, De Santis A et al. (1996) Mechanisms involved in the in vitro modification of low density lipoprotein by human umbilical vein endothelial cells and copper ions. J Lipid Med Cell Sign 13: 19-33

39. Steel RGD, Torrie JH (1960) Principles and procedures of statistics. McGraw-Hill Book, New York

40. Draper N, Smith H (1966) Applied regression analysis. Wiley, New York

41. Cominacini L, Zocca I, Garbin U et al. (1988) High-density lipoprotein composition in obesity: interrelationships with plasma insulin levels and body weight. Int J Obesity 12: 343-352

42. Fasching P, Waldhausl W, Wagner OF (1996) Elevated circulating adhesion molecules in non-insulin-dependent diabetes mellitus- potential mediators in diabetic macroangiopathy. Diabetologia 39: 1242-1244

43. Cominacini L, Garbin U, Pastorino AM, et al. (1994) Role of oxidized low density lipoproteins in the pathogenesis of atherosclerosis. Eur J Lab Med 2: 43-50 